\title{
ACúmulo de Macro e Micronutrientes POR SOJA E Brachiaria brizantha EMERGIDA EM DIFERENTES ÉPOCAS
}

\author{
Accumulation of Macro and Micronutrients by Soybean and Brachiaria brizantha Emerged in \\ Different Periods
}

\begin{abstract}
SILVA, A.C. ${ }^{2}$, FREITAS, R.S. ${ }^{3}$, FERREIRA, L.R. ${ }^{4}$ e FONTES, P.C.R. ${ }^{4}$
RESUMO - A rotação entre soja e $B$. brizantha tem sido muito utilizada na integração agricultura-pecuária. Contudo, o banco de sementes formado pela pastagem anterior torna a forrageira uma espécie daninha importante no cultivo da soja. Objetivou-se neste trabalho avaliar os efeitos de diferentes épocas de emergência de $B$. brizantha em relação à soja no acúmulo de macro e micronutrientes por ambas as espécies. O experimento foi realizado em casa de vegetação, avaliando-se sete épocas de emergência de $B$. brizantha em relação à emergência da soja, sendo: $-21,-14$ e -7 dias, as épocas da emergência da braquiária antes da emergência da soja (DA); 0 , a emergência simultânea da soja e da braquiária; e 7, 14 e 21 dias, as épocas de emergência da braquiária depois da soja (DD), além de duas testemunhas (apenas soja ou $B$. brizantha), no delineamento experimental inteiramente casualizado. A avaliação nutricional das plantas foi realizada no estádio de pleno florescimento da soja. Na emergência simultânea das espécies, $B$. brizantha apresentou maior acúmulo de $\mathrm{N}, \mathrm{P}, \mathrm{K}, \mathrm{S}, \mathrm{Mg}, \mathrm{Cu}, \mathrm{Mn}$ e Fe, enquanto a soja acumulou mais $\mathrm{Ca}, \mathrm{Zn}$ e $\mathrm{B}$. A soja obteve vantagem no acúmulo dos demais nutrientes quando a forrageira emergiu em torno de $7 \mathrm{DD}$, com máximo acúmulo quando $B$. brizantha emergiu aos 21 DD.
\end{abstract}

Palavras-chave: braquiária, competição, Glycine max, nutrição mineral.

\begin{abstract}
Soybean and Brachiaria brizantha rotation has been frequently used in crop-livestock integration. However, the pasture seed bank makes forage an important weed in soybean growing areas. This study aimed to quantify the effects of different B. brizantha emergence periods in relation to soybean on macro and micronutrient accumulation by both species. This study was conducted under greenhouse conditions, with the following seven emergence periods of $\boldsymbol{B}$. brizantha being evaluated in relation to soybean:: $-21,-14,-7$ days, emergence periods of the $\boldsymbol{B}$. brizantha before the emergence of soybean (DB), $O$, simultaneous emergence of soybean and B. brizantha; 7,14 and 21 days, emergence periods of B. brizantha after soybean (DA) plus two controls (soybean or B. brizantha alone), in a randomized complete design, with four replications. The nutritional evaluation of both species was performed when soybean reached full-flower stage. In the simultaneous emergence of both species, B. brizantha presented greater $N, P, K, S, M g$ and Fe accumulation while soybean accumulated more $\mathrm{Ca}, \mathrm{Zn}$ and $\mathrm{B}$. When forage emergence occurred about $7 \mathrm{DA}$, soybean plants showed greater accumulation of all nutrients, reaching maximum accumulation with B. brizantha emergence at 21 DA.
\end{abstract}

Keywords: Brachiaria, competition, Glycine max, mineral nutrition.

Recebido para publicação em 18.1.2008 e na forma revisada em 18.2.2009.

2 Agência Paulista de Tecnologia dos Agronegócios (APTA), Polo Regional da Alta Sorocabana, Caixa Postal 298, 19001-970 Presidente Prudente-SP, <andreiacs@apta.sp.gov.br>; ${ }^{3}$ APTA, Polo Regional do Noroeste Paulista, Votuporanga-SP, <freitas@apta.sp.gov.br>; ${ }^{4}$ Universidade Federal de Viçosa, Departamento de Fitotecnia, 36571-000, Viçosa-MG, <1roberto@ufv.br, parecefo@ufv.br>. 


\section{INTRODUÇÃO}

O cultivo da soja (Glycine max) tem sido uma das principais opções para recuperação e renovação de pastagens degradadas no cerrado brasileiro, e a rotação da soja com pastagem (dois a três anos) tem propiciado beneficios a ambas as culturas (Kichel et al., 2000). Nesse sistema, a espécie forrageira é dessecada para o plantio direto da soja. Todavia, nessas áreas, a forrageira se torna a principal espécie daninha que compete com a soja, devido ao banco de sementes formado pela pastagem anterior.

Os nutrientes são um dos fatores passivieis de competição por essas plantas. Os padrões dos efeitos da competição por esse fator são determinados, em parte, por aspectos específicos dos competidores, como é o caso da fixação simbiótica de nitrogênio pela soja, e também pelas diferenças no hábito de crescimento e requerimento de nutrientes pelas espécies envolvidas (Pitelli et al., 1983). Algumas espécies de plantas daninhas são mais competitivas com as culturas devido à sua maior eficiência na absorção e utilização de nutrientes (Tomaso, 1995). Portanto, mesmo que diferentes espécies vegetais apresentem capacidade similar na absorção de determinado nutriente, pode ocorrer grande diferença entre elas na produção de biomassa (Furlani et al., 1986). Segundo Rizzardi et al. (2001), a intensidade de competição entre raízes das plantas daninhas e da cultura pelos recursos existentes abaixo da superficie do solo depende do tipo e da disponibilidade dos recursos, da espécie vegetal e de sua capacidade em desenvolver sistema radical extenso, com diâmetro reduzido e área superficial ampla.

Diversos trabalhos mostram que as espécies daninhas apresentam capacidade distinta de competição com a soja (Chemale \& Fleck, 1982; Pitelli et al., 1983; Voll et al., 2002; Fleck et al., 2004; Rizzardi et al., 2004). Estudos sobre competição relativa de espécies daninhas com cultivares de soja mostraram que espécies como Brachiaria plantaginea, Ipomoea grandifolia, Euphorbia heterophylla e Senna obtusifolia reduziram a produtividade da soja de forma distinta, com decréscimos de 19, 25, 32 e $47 \%$, respectivamente (Voll et al., 2002).

A época de emergência das plantas daninhas também tem grande contribuição na interação competitiva das espécies. De acordo com Kropff \& Lotz (1992), 96\% das variações na redução de rendimento da soja foram explicadas pela variação na época de emergência das plantas daninhas; apenas $13 \%$ das diferenças de produtividade foram explicadas pela variação na densidade dessas plantas. Rizzardi et al. (2004) verificaram que a época de emergência das plantas daninhas, em relação à cultura da soja, influenciou a intensidade de redução de biomassa da cultura. Fleck et al. (2004) relataram que o atraso na emergência da soja em relação a picão-preto e guanxuma aumenta os efeitos negativos dessas espécies sobre a cultura, os quais são potencializados pelo incremento da densidade, principalmente em relação ao picão-preto. Exley \& Snaydon (1992) constataram que a época relativa de emergência teve efeito mais intenso de competição no desenvolvimento da cultura e da planta daninha em nivel radical. O efeito da época relativa de emergência é importante porque influencia a velocidade de estabelecimento da planta daninha e a intensidade das interações das espécies.

$\mathrm{O}$ acúmulo de nutrientes tem sido mais utilizado no estudo da competição entre plantas do que o teor. Isso ocorre devido ao fato de que determinada espécie pode apresentar maior teor do nutriente, mas, devido à baixa produção de biomassa, obtém menor acúmulo (Pitelli, 1985).

Neste trabalho, objetivou-se avaliar a interferência de $B$. brizantha, emergida em diferentes épocas em relação à cultura da soja, sobre o acúmulo de macro e micronutrientes dessas espécies, em condições controladas.

\section{MATERIAL E MÉTODOS}

O experimento foi conduzido em casa de vegetação do Departamento de Fitotecnia da Universidade Federal de Viçosa, no período de novembro de 2003 a abril de 2004. As plantas foram cultivadas em vasos com 6,0 L de substrato (mistura de Argissolo Vermelho-Amarelo câmbico, fase terraço, e areia, na proporção de 2,5:1, respectivamente, acrescida de $250 \mathrm{mg}$ de superfosfato simples por vaso). Durante o desenvolvimento do experimento foram feitas adubações periódicas de cobertura, com solução contendo macro e micronutrientes. Para 
simular alta infestação de braquiária em cada vaso, foram utilizadas três plantas de $B$. brizantha cv. MG5 e uma de soja cv. UFV 16, que representou uma unidade experimental. As sementes de soja foram inoculadas com as estirpes SEMIA 587 e SEMIA 5019 de Bradyrhizobium japonicum antes da semeadura, que foi realizada em 16/12/2003.

Os tratamentos constaram de sete épocas de emergência de $B$. brizantha em relação à emergência da soja, sendo: $-21,-14$ e -7 , as épocas da emergência da braquiária antes da emergência da soja (DA); 0, a emergência simultânea da soja e da braquiária; e 7, 14 e 21 dias, as épocas de emergência da braquiária depois a da soja (DD), além de duas testemunhas (apenas soja ou $B$. brizantha). Adotouse delineamento inteiramente casualizado, com quatro repetições.

$B$. brizantha foi semeada diretamente nos vasos. O primeiro tratamento $(B$. brizantha emergida 21 dias antes da soja) foi semeado em 25/11/2003. As semeaduras seguintes ocorreram a intervalos de sete dias, de forma que a emergência coincidisse com os períodos predeterminados, sendo posteriormente desbastadas para três plantas. Assim, o trabalho baseia-se numa área altamente infestada $\left(84\right.$ plantas por $\mathrm{m}^{2}$ ) com $B$. brizantha (proporção $3: 1$ ).

As folhas das espécies foram coletadas quando as plantas de soja atingiram o estádio fenológico de pleno florescimento (estádio R2), segundo escala de Fehr et al. (1971). As folhas de $B$. brizantha e da soja foram secas em estufa de ventilação forçada de ar a $70{ }^{\circ} \mathrm{C} \pm 2{ }^{\circ} \mathrm{C}$ até atingir massa constante, sendo posteriormente moídas em moinho tipo Wiley. As amostras destinadas à determinação do $\mathrm{N}$ foram submetidas à digestão sulfúrica, sendo este determinado por calorimetria, usando o reagente de Nessler (Jackson, 1958). Para determinação de $\mathrm{P}$ e $\mathrm{S}$, as amostras foram submetidas à digestão nítrico-perclórica (Johnson \& Ulrich, 1959); com os extratos obtidos, determinou-se a concentração de K, pelo método de fotometria de chama, e as concentrações de Ca e Mg, por espectrofotometria de absorção atômica (Malavolta et al., 1997).

As amostras destinadas à determinação do $\mathrm{B}$ foram submetidas à digestão via seca, e para $\mathrm{Zn}, \mathrm{Cu}, \mathrm{Fe}$ e $\mathrm{Mn}$ o material foi digerido em mistura nítrico-perclórica (Johnson \& Ulrich, 1959). A seguir, o material foi analisado quimicamente, para determinação dos teores dos respectivos elementos, por espectrofotometria de absorção atômica (Malavolta et al., 1997). O acúmulo dos nutrientes nas folhas das espécies foi obtido multiplicando-se o teor do nutriente pela massa seca das folhas.

Os dados foram submetidos à análise de variância, e as estimativas dos parâmetros da regressão do modelo foram obtidas utilizandose o programa SIGMAPLOT, em que se adotouse o modelo sigmoidal: $Y=\mathrm{a} /(1+\exp (-(\mathrm{x}-\mathrm{x} 0) / \mathrm{b}))$.

\section{RESULTADOS E DISCUSSÃO}

A época de emergência de $B$. brizantha em relação à da soja foi determinante no desenvolvimento de ambas as espécies (Figura 1), concordando com outros trabalhos desenvolvidos com soja (Fleck et al., 2004; Rizzardi et al., 2004). O maior acúmulo de massa seca das folhas de soja (18 g por vaso) ocorreu quando a forrageira emergiu 21 dias depois da soja (DD) e correspondeu a $38 \%$ do maior acúmulo obtido por $B$. brizantha, o que ocorreu quando esta emergiu 21 dias antes (DA) da soja (47 g por vaso). Todavia, a soja apresentou vantagem em relação a $B$. brizantha quando a forrageira emergiu a partir de $4 \mathrm{DD}$, o que é explicado pelo sombreamento exercido pela soja, que comprometeu o pleno estabelecimento da forrageira.

Diferentemente do que ocorreu com a massa seca, o maior acúmulo de $\mathrm{N}$ obtido pela soja foi apenas 9,5\% menor que o alcançado pela forrageira (Figura 2). É importante destacar que os teores de $\mathrm{N}$ nas folhas de $B$. brizantha foram bem inferiores aos da soja (Tabela 1). A soja apresentou, em média, o dobro do teor de $\mathrm{N}$ de $B$. brizantha, confirmando o exposto por Pitelli et al. (1983), de que os padrões dos efeitos da competição por nutrientes são determinados, em parte, por aspectos específicos dos competidores, como é o caso da fixação simbiótica de nitrogênio pela soja.

Os macro e micronutrientes apresentaram comportamento análogo ao observado para a massa seca das folhas, ou seja, o maior acúmulo de nutrientes obtido pela soja e por 
$B$. brizantha ocorreu quando a forrageira emergiu aos $21 \mathrm{DD}$ e aos $21 \mathrm{DA}$, respectivamente. Assim, a espécie que se estabeleceu primeiro apresentou maior crescimento e, consequentemente, maior acúmulo de nutrientes.

Embora B. brizantha tenha apresentado teores de $\mathrm{P}$ próximos aos da soja (Tabela 1), obteve o dobro (113 mg por vaso) do maior acúmulo da soja (52 mg por vaso) (Figura 2). Estudos realizados com $B$. brizantha por Faquin et al. (2000), em latossolos de cerrado, mostraram que os sintomas de deficiência de $\mathrm{P}$ na forrageira foram os mais severos. Esse fato evidencia a importância desse nutriente no estabelecimento dessa espécie. Considerando a rotação com soja, incorporada como cobertura morta, a forrageira torna-se importante na reciclagem desse nutriente, corroborando os resultados publicados por Magalhães (1997), que apontam $B$. brizantha como boa espécie na ciclagem de nutrientes.

Comparando o acúmulo máximo de $\mathrm{K}$ obtido pelas espécies, também se verificou (Figura 2) vantagem de $B$. brizantha $(387 \mathrm{mg}$ por vaso) em relação à soja (207 mg por vaso). Na Tabela 1 verifica-se que os teores de $P$ e principalmente de $\mathrm{K}$ no tecido foliar de $B$. brizantha foram maiores nos tratamentos de maior competição com a soja. Segundo Minson (1990), esse comportamento ocorre porque plantas que cresceram sob radiação

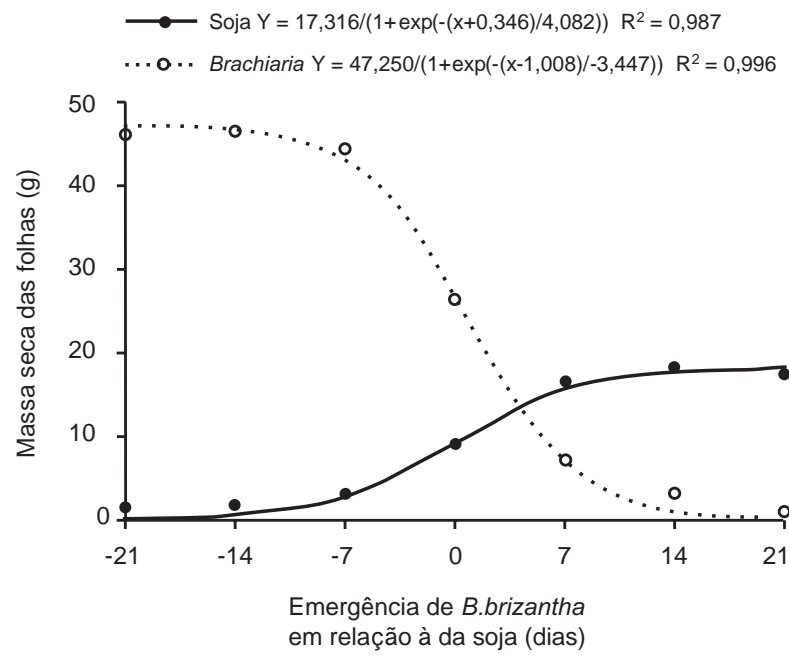

Figura 1 - Massa seca de folhas de soja e B. brizantha (g por vaso) emergida em diferentes épocas em relação à soja. Viçosa-MG, 2004 solar direta, sem atraso no desenvolvimento vegetativo, tendem a reduzir os níveis de $\mathrm{P}$ na
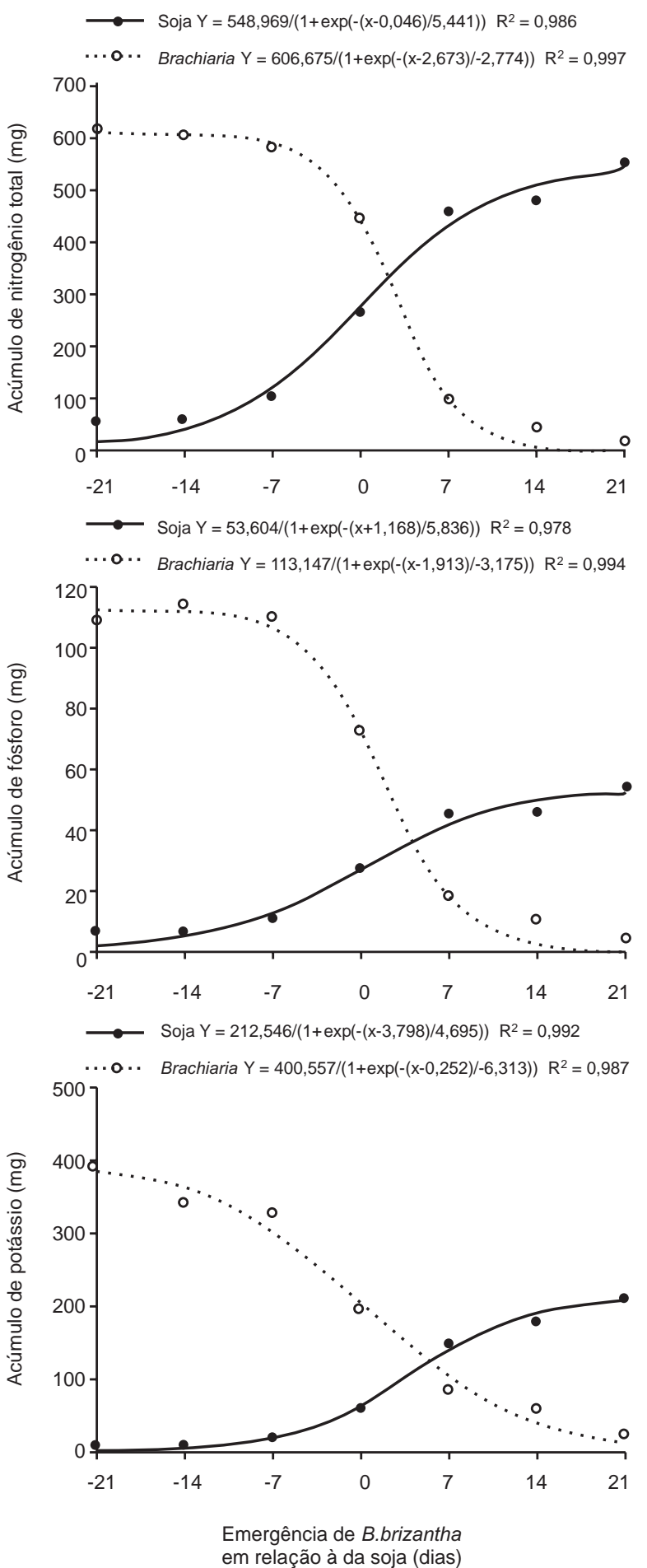

Figura 2 - Acúmulo de nitrogênio, fósforo e potássio por folhas de soja e $B$. brizantha (mg por vaso) emergida em diferentes épocas em relação à soja. Viçosa-MG, 2004. 
Tabela 1 - Teores de macro e micronutrientes em folhas de soja $\left(\mathrm{S}_{\mathrm{o}}\right)$ e B. brizantha $\left(\mathrm{B}_{\mathrm{r}}\right)$ emergida em diferentes épocas em relação à soja

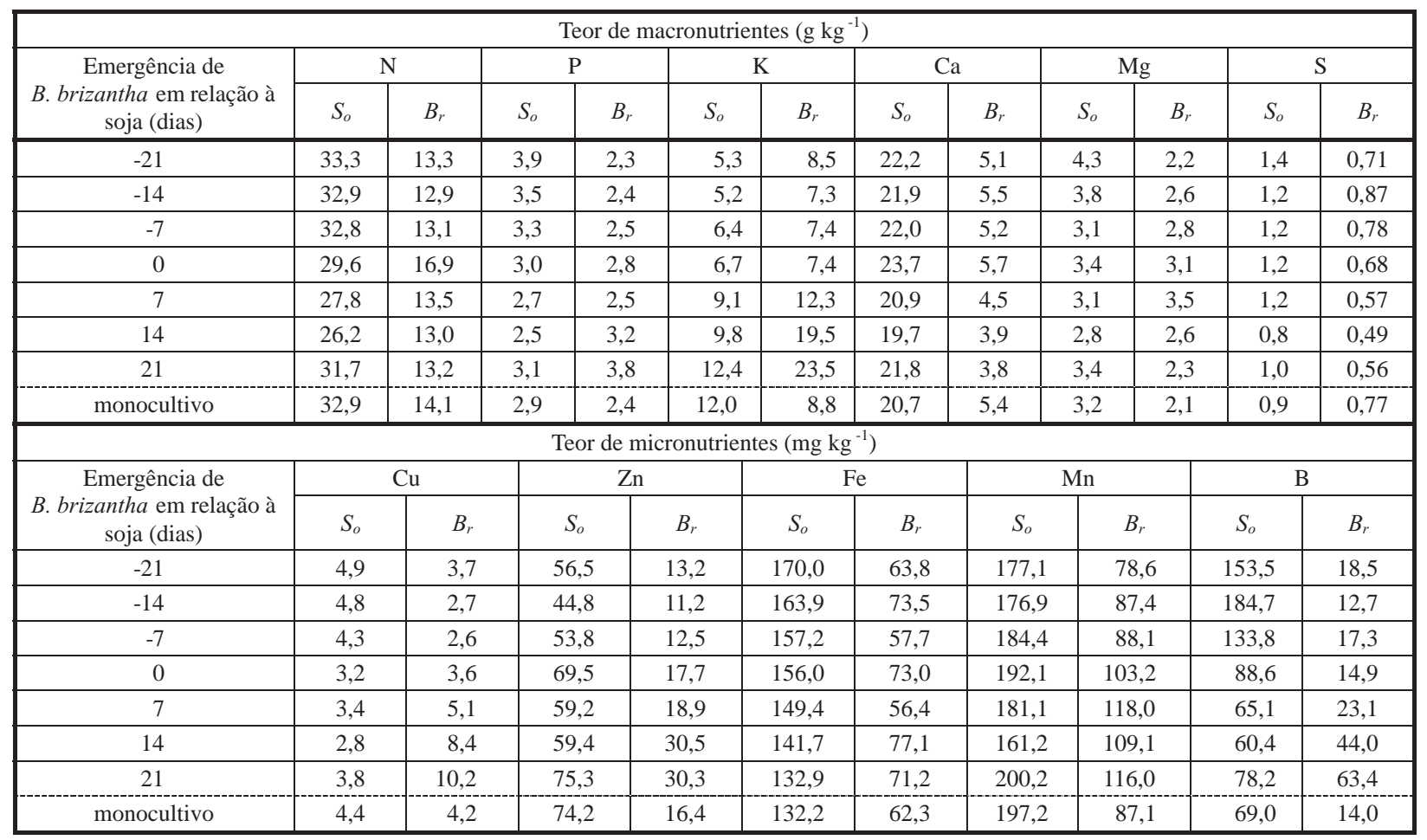

biomassa, em decorrência da redistribuição desse elemento dentro da planta. Carvalho et al. (1995) atribuem maiores teores de K nas folhas de $B$. brizantha sombreada a seu menor rendimento forrageiro.

Na emergência simultânea das espécies, a soja acumulou apenas 62, 37 e 32\% do N, P e $\mathrm{K}$ acumulado por $B$. brizantha, respectivamente, evidenciando vantagem da forrageira no acúmulo de nutrientes. Entretanto, quando a forrageira emergiu aos $21 \mathrm{DD}$, ela acumulou apenas $6,5,1,8$ e 7,2\% do N, P e K acumulado pela soja, respectivamente. Jakelaitis (2004) verificou que $B$. brizantha em monocultivo extraiu 97, 59 e $30 \mathrm{~kg} \mathrm{ha}^{-1}$ de $\mathrm{K}, \mathrm{N}$ e P, respectivamente; quando consorciada com milho, extraiu 19, 12 e $7 \mathrm{~kg} \mathrm{ha}^{-1}$ nos respectivos tratamentos, o que demonstra o impacto da competição no acúmulo de nutrientes pela forrageira.

A soja obteve acúmulo máximo de $378 \mathrm{mg}$ de $\mathrm{Ca}$, e $B$. brizantha, de $247 \mathrm{mg}$ (Figura 3). Embora a soja tenha apresentado menor acúmulo de massa seca, o teor deste elemento em suas folhas foi cerca de quatro vezes maior que o da forrageira (Tabela 1), o que conferiu maior acúmulo do nutriente. Na emergência simultânea das espécies, $B$. brizantha acumulou apenas $69 \%$ do $\mathrm{Ca}$ acumulado pela soja, o que demonstra o grande potencial dessa leguminosa em acumular Ca. Pitelli et al. (1983) verificaram no estudo da competição de soja com Cyperus rotundus que o teor de Ca nos tecidos da leguminosa foi o triplo do apresentado pela espécie daninha.

Quanto a Mg e S (Figura 3), o acúmulo máximo pela soja por vaso foi muito menor que o de $B$. brizantha $(57$ e $118 \mathrm{mg}$ de $\mathrm{Mg}$ e 16 e $37 \mathrm{mg}$ de $\mathrm{S}$, para soja e $B$. brizantha, respectivamente). Quando emergiram simultaneamente, a soja acumulou $31 \%$ do $\mathrm{Mg}$ e $36 \%$ do $\mathrm{S}$, em relação a $B$. brizantha.

Em relação aos micronutrientes, a soja apresentou acúmulo menor de $\mathrm{Cu}$ e maior de Zn e B (Figura 4), comparada a B. brizantha. O acúmulo máximo nas folhas de soja foi de 0,06 , 1,24 e 1,33 mg de $\mathrm{Cu}, \mathrm{Zn}$ e B por vaso, respectivamente. $\mathrm{Na} B$. brizantha, o acúmulo máximo foi de 0,16, 0,57 e 0,79 $\mathrm{mg}$ de $\mathrm{Cu}, \mathrm{Zn}$ e B por vaso, respectivamente. 

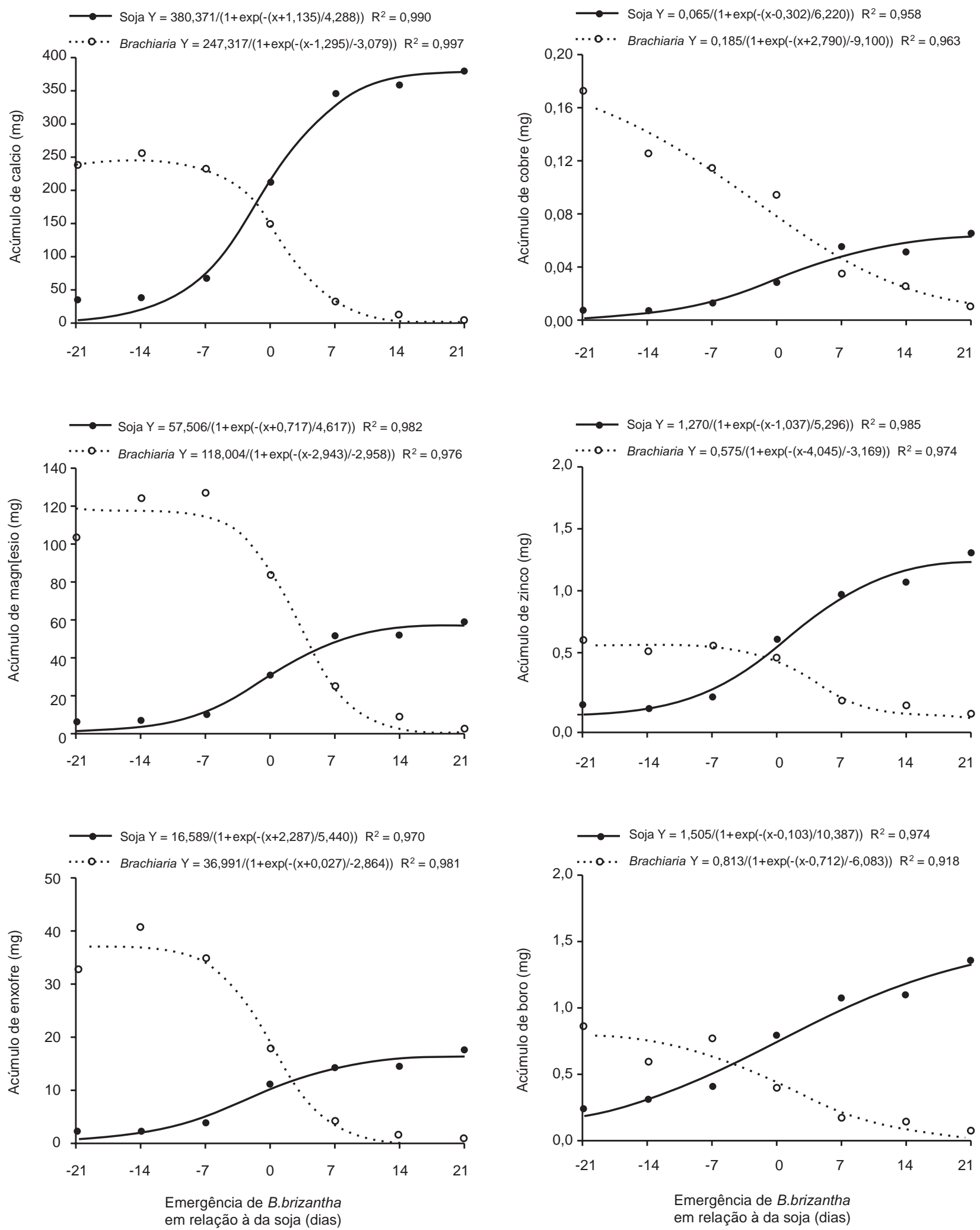

Figura 3 - Acúmulo de cálcio, magnésio e enxofre por folhas de soja e $B$. brizantha (mg por vaso) emergida em diferentes épocas em relação à soja. Viçosa-MG, 2004.

Figura 4 - Acúmulo de cobre, zinco e boro por folhas de soja e $B$. brizantha (mg por vaso) emergida em diferentes épocas em relação à soja. Viçosa-MG, 2004. 
A soja acumulou mais $Z n$ e B mesmo quando emergiu simultaneamente com B. brizantha. Esta acumulou $78 \%$ do $Z$ n e $57 \%$ do $\mathrm{B}$ acumulado pela leguminosa. O maior acúmulo desses elementos pela soja deveuse aos maiores teores deles em seu tecido foliar (Tabela 1). Faquin et al. (2000) demonstraram que $B$. brizantha e soja foram menos afetadas por omissão de micro que de macronutrientes.

$\mathrm{O}$ acúmulo máximo de $\mathrm{Fe}$ e $\mathrm{Mn}$ pela forrageira foi maior que o da soja; verificou-se acúmulo de 2,6 e 3,1 mg de Fe por vaso e de 3,4 e 3,9 mg de Mn por vaso (Figura 5), para soja e $B$. brizantha respectivamente. De modo geral,

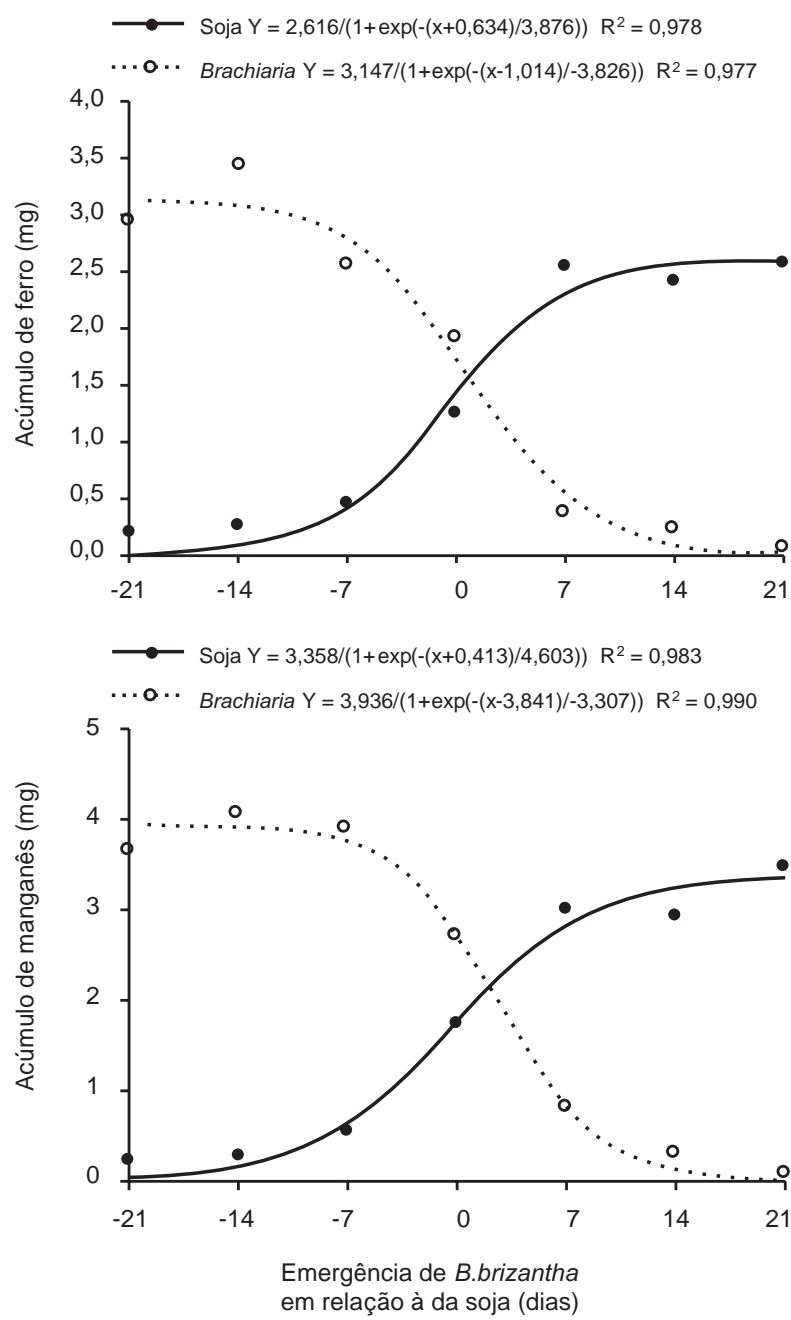

Figura 5 - Acúmulo de ferro e manganês por folhas de soja e $B$. brizantha (mg por vaso) emergida em diferentes épocas em relação à soja. Viçosa-MG, 2004. os teores desses nutrientes foram maiores na soja (Tabela 1); todavia, como $B$. brizantha acumulou maior quantidade de massa seca, obteve maior acúmulo desses nutrientes.

Brachiaria brizantha obtém maior acúmulo de $\mathrm{N}, \mathrm{P}, \mathrm{K}, \mathrm{S}, \mathrm{Mg}, \mathrm{Cu}, \mathrm{Mn}$ e Fe, e a soja, de $\mathrm{Ca}, \mathrm{Zn}$ e B, quando emergem simultaneamente. Quando a forrageira emerge em torno de sete dias após a leguminosa, esta passa a obter vantagem no acúmulo desses nutrientes.

\section{LITERATURA CITADA}

CARVALHO, M. M.; FREITAS, V. P.; ANDRADE, A. C. Crescimento inicial de cinco gramíneas tropicais em um sub-bosque de angico-vermelho (Anadenanthera macrocarpa Benth). Past. Trop., v. 17, n. 1, p. 24-30, 1995.

CHEMALE, V. M.; FLECK, N. G. Avaliação de cultivares de soja (Glycine max (L.) Merrill) em competição com Euphorbia heterophylla L. sob três densidades e dois períodos de ocorrência. Planta Daninha, v. 2, n. 1, p. $36-45,1982$.

EXLEY, D. M.; SNAYDON, R. W. Effects of nitrogen fertilizer and emergence date on root and shot competition between wheat and blackgrass. Weed Res., v. 32, n. 3 , p. 175-182, 1992.

FAQUIN, V. et al. Nutrição mineral do braquiarão e da soja cultivados em latossolos sob cerrado da região de Cuiabá MT. Ci. Agrotecnol., v. 24, n. 1, p. 110-117, 2000.

FEHR, W. R. et al. Stage of development descriptions for soybeans, Glycine $\max (\mathrm{L}$.) Merrill. Crop Sci., v. 11, n. 6, p. 929-931, 1971.

FLECK, N. G. et al. Interferência de picão-preto e guanxuma com a soja: efeitos da densidade de plantas e época relativa de emergência. Ci. Rural, v. 34, n. 1, p. 41-48, 2004.

FURLANI, A. M. C.; BATAGLIA, O. C.; AZZINI, L. E. Variabilidade entre linhagens de arroz na absorção e utilização de potássio em solução nutritiva. R. Bras. Ci. Solo, v. 10, n. 1, p. 135-141, 1986.

JACKSON, M. L. Soil chemical analysis. Englewood Cliffs: Prentice-Hall, 1958. 458 p.

JAKELAITIS, A. Técnicas para implantação do consórcio milho com Brachiaria spp. 2004. 93 f. Tese (Doutorado em Fitotecnia) - Universidade Federal de Viçosa, Viçosa, MG, 2004. 
JOHNSON, C. M.; ULRICH, A. Analytical methods for use in plants analyses. Los Angeles: University of California, 1959. p. 32-33 (Bulletin, 766).

KICHEL, A. N.; MIRANDA, C. H. B.; TAMBOSI, S. A. T. Produção de bovinos de corte com a integração agricultura $\mathrm{x}$ pecuária. In: SIMPÓSIO DE FORRAGICULTURA E PASTAGENS: TEMAS EM EVIDÊNCIAS, 1., 2000, Lavras Anais... Lavras: Universidade Federal de Lavras, 2000. p. 51-68.

KROPFF, M. J.; LOTZ, L. A. P. Optmization of weed management systems: the role of ecological models of interplant competition. Weed Technol., v. 6, n. 2, p. $462-470,1992$.

MAGALHÃES, R. T. Evolução das propriedades físicas e químicas de solos submetidos ao manejo pelo Sistema Barreirão. 1997. 86 f. Dissertação (Mestrado em Fitotecnia) - Universidade Federal de Goiás, Goiânia, 1997.

MALAVOLTA, E.; VITTI, G. C.; OLIVEIRA, S. A. Avaliação do estado nutricional das plantas: princípios e aplicações. 2.ed. Piracicaba: Potafos, 1997. 319 p.

MINSON, D. J. Forage in ruminant nutrition. San Diego: Academic Press, 1990. 483 p.
PITELLI, R. A. Interferência de plantas daninhas em culturas agrícolas. Inf. Agropec., v. 120, n. 11, p. 16-27, 1985.

PITELLI, R. A.; DURIGAN, J. C.; BENEDETTI, N. J. Estudo de competição inter e intraespecífica envolvendo Glycine max (L.) Merril e Cyperus rotundus (L.), em condições de casa de vegetação. Planta Daninha, v. 6, n. 2, p. $129-137,1983$.

RIZZARDI, M. A. et al. Competição por recursos do solo entre ervas daninhas e culturas. Ci. Rural, v. 31, n. 4, p. $707-714,2001$

RIZZARDI, M. A. et al. Interferência de populações de Euphorbia heterophylla e Ipomoea ramosissima isoladas ou em misturas sobre a cultura da soja. Planta Daninha, v. 22, n. 1, p. 29-34, 2004.

TOMASO, J. M. Approaches for improving crop competitiveness through the manipulation of fertilization strategies. Weed Sci., v. 43, p. 491-497, 1995.

VOLL, E. et al. Competição relativa de espécies de plantas daninhas com dois cultivares de soja. Planta Daninha, v. 20, n. 1, p. $17-24,2002$ 